\title{
A stable reference frame for the study of ground deformation in the Houston metropolitan area, Texas
}

\author{
Research Article \\ G. Wang*, J. Yu, J. Ortega, G. Saenz, T. Burrough and R. Neill
}

National Center for Airborne Laser Mapping, Department of Earth and Atmospheric Sciences, University of Houston, Houston, TX 77004

\begin{abstract}
:
A great number of GPS stations have been installed in the Houston, Texas area for studying ground deformation caused by subsidence, salt dome uplift, and fault creep. One major consideration in determining the magnitude and velocity of ground displacement over time using GPS, particularly for horizontal ground deformations, is the selection of reference frames. In this study, we define a Stable Houston Reference Frame (SHRF) using over 8-year of continuous data from 10 permanent GPS stations. These stations are located throughout Harries County and nearby counties, and cover an area of about $200,000 \mathrm{~km}^{2}$. The realization of SHRF is defined in terms of a Helmert transformation from the International GNSS (Global Navigation Satellite System) Reference Frame of 2008 (IGS08). SHRF is aligned with the IGS08 at epoch 2012.0. The velocities of these 10 frame stations are minimized to zero within the stable reference frame. The GIPSY/OASIS (V6.1.2) software package was used to calculate position coordinates within IGS08. The precise point positioning (PPP) daily solutions within SHRF achieve 2-3 mm horizontal accuracy and 6-7 mm vertical accuracy. The main results of this article include (1) accurate global (IGS08) positions and velocities of 10 selected frame sites, and (2) 14 parameters for reference frame transformation from IGS08 to SHRF. SHRF will be incrementally improved and be synchronized with the update of IGS reference frame.
\end{abstract}

\section{Keywords:}

Fault creep • GPS $•$ Helmert transformation $•$ Houston $•$ IGS08 $•$ Local reference frame $•$ Subsidence

(c) Versita sp. z o.o.

Received 19-05-2013; accepted 09-07-2013

\section{Introduction}

The Houston metropolitan area of Texas, as described in this article, includes all of Harris County and Galveston County, and parts of surrounding counties, Brazoria, Fort Bend, Waller, Montgomery, Liberty, and Chambers Counties. Houston provides the most recognized case study of subsidence and fault creeping problems afflicting a U.S. metropolitan area. Accumulated subsidence of over 3 meters during the past 100 years has been observed in a large area of southeast Houston, including the cities of Pasadena, Baytown, Texas City, and Galveston (Kasmarek et al., 2009). More than 150 historically active faults have been identified in the greater

\footnotetext{
*E-mail: gwang@uh.edu
}

VERSITA
Houston area (e.g., Shah and Lanning-Rush, 2005). These creeping faults have caused moderate to severe damage to hundreds of residential, commercial, and industrial structures in the Houston area, where the foundation repair industry thrives. To prevent land subsidence, the Texas Legislature created the Harris-Galveston Subsidence District (HGSD) in 1975 and the Fort Bend Subsidence District (FBSD) in 1989. The primary obligation of both districts is to regulate and reduce groundwater withdrawal in order to prevent ground subsidence that contributes to flooding in this area (HGSD 2010, FBSD 2009). The two districts maintain a campaignstyle GPS network with more than seventy permanent GPS monuments (Fig. 1). These campaign GPS stations are also called PortA-Measure (PAM) stations (Zilkoski et al., 2003). On average, the subsidence districts collect GPS data at each PAM site for one week per two months. The earliest campaign GPS surveying began in 
1993, and has accumulated a large set of valuable data for studying subsidence over time and space. In addition to the PAM GPS network, there are currently more than twenty Continuously Operating Reference Stations (CORS) in the Houston area (Wang and Soler, 2013). These CORS sites are operated by the Texas Department of Transportation, the City of Houston, and other local agencies. Recently, National Science Foundation (NSF) awarded the University of Houston with a research project (2012-2015) to establish a realtime GPS network with 40 permanent stations in the Houston area for the study of multiple urban natural hazards, including subsidence, faulting, salt dome uplift, flooding, and hurricane intensity forecasts. Houston experiences ground instability problems in several ways, from subsidence and fault movements that slowly crack infrastructure and building foundations, to rapid changes in the ground elevation during severe droughts or flooding caused by hurricanes and storms. These current and future GPS stations will provide fundamental observations for studying local ground deformation and minimizing hazards associated with ground instability.

\section{The need for a local reference frame in the Houston area}

The need for a consistent and stable reference frame to precisely interpret local ground deformation has become critically important since the early 1990s when the Harris-Galveston and Fort Bend subsidence districts and the National Geodetic Survey (NGS) were using GPS observations to measure local subsidence. It is difficult to identify stable benchmarks in the Houston area, because of the broad extent of subsidence. In order to provide stable references, the Harris-Galveston subsidence district, U.S. Geological Survey (USGS), and NGS installed three GPS antennas on the inner pipes of three deep borehole extensometers located in the center of the city of Houston (Fig. 1). Continuous GPS monitoring at these three sites started as early as 1993. The scientific theory and operation of a borehole extensometer are explained by Poland et al. (1984) and Gabrysch (1984). To install a borehole extensometer, a borehole was firstly drilled to a predetermined depth. A steel outer casing with slip joints was installed in the borehole. A smaller diameter pipe (inner piper) was then inserted inside the outer casing. The inner pipe was anchored to a concrete plug at the bottom of the borehole and extends to the ground surface (Zilkoski et al., 2003). An extensometer measures the accumulative compaction of strata between the land surface and the bottom of the borehole, while the co-located GPS antenna measures the absolute displacement at the bottom of the borehole. According to the well log and local geological information, the strata at the base of the boreholes are below the zones in the aquifer system that could be affected by compaction (Zilkoski et al., 2003, Kasmarek et al., 2012). Therefore, they are assumed to be stable. Continuous GPS position time series at these three deeply anchored GPS sites also indicate that there have been no considerable vertical displacements for the past 19 years (19942012) (Wang and Soler, 2013). These deeply anchored GPS stations have been used as stable references to extract ground deformation information at PAM sites using the single-base carrier phase double difference method by the subsidence districts (http: // mapper subsidence .org/Chartindex . htm) and other researchers (e.g., Zilkoski et al., 2003; Engelkemeir et al., 2010). The use of one or more individual reference stations over time and space makes the direct combination and comparison of velocity vectors very difficult, especially for those stations located at greater distances (e.g., $>40 \mathrm{~km}$ ) from these references since the accuracy of differential GPS solutions decreases with the increase of baseline length (e.g., Eckl et al., 2001; Wang, 2011; Wang and Soler, 2012). Errors occurred in the reference positions would propagate to final positions of rover stations in the differential processing. Furthermore, the positions of rover stations would not be solved if the reference station misses data. These problems can be overcome with the use of a consistent and stable reference frame over time by adopting the same rigorous approach used to describe plate tectonic motions.

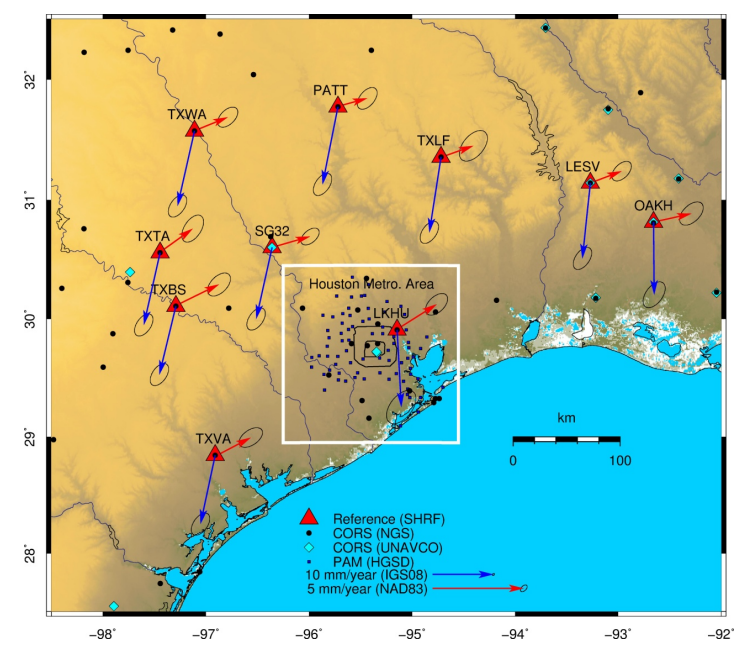

Figure 1. Map showing the locations of 10 frame sites used to realize the Stable Houston Reference Frame (SHRF), which were selected from about 50 Continuously Operating Reference Stations (CORS) whose data are archived at NGS and UNAVCO. The horizontal velocity vectors are referred to IGS08 (blue, about $15 \mathrm{~mm} /$ year) and NAD83(2011) (red, about $2 \mathrm{~mm} /$ year).

A complex part of GPS data is that they initially provide position coordinates in a global reference frame, such as the International GNSS Service Reference Frame of 2008 (IGS08) (Rebischung et al., 2012). All sites are moving within a global reference frame as shown in Fig. 1. However, most researchers are interested in regional or local ground deformations. A regional or local reference frame will therefore make it easier to interpret site-specific ground deformations over time and space. Several continental-scale reference frames fixed on the North America Plate have been developed by the geodetic community, such as the Stable North American Reference Frame

\section{VERSITA}


(SNARF, http://www.unavco.org/community_science/ workinggroups_projects/snarf/snarf.html), North American Reference Frame (NAREF, http : / www . naref .org), North American Frame 2012 (NA12) (Blewitt et al., 2012), and the North American Datum of 1983 (NAD83) (Schwarz, 1989; Snay and Soler, 2000). NAD83(2011) is the latest realization of the North American tectonic plate-fixed reference frame maintained by NGS. These large scale reference frames are realized with an approach of minimizing overall movements of a large number of selected frame stations distributed in North America. Figure 1 shows locations of 10 reference stations and their velocity vectors referred to both the global reference frame IGS08 and the continental-scale reference frame NAD83(2011). The average horizontal velocities in the Houston metropolitan area are approximately $15 \mathrm{~mm} /$ year toward southwest within IGS08 and $2 \mathrm{~mm}$ per year toward northeast within NAD83. There are no strictly stable sites within NAD83 in the Houston area. Local ground deformation information has been biased by the large reference frame. A stable reference frame covering a small area will minimize the biases occurred in a continental-scale reference frame and highlight site-specific local ground deformations. This study aims to establish a high-accuracy local reference frame, Stable Houston Reference Frame (SHRF), covering an area of about $200,000 \mathrm{~km}^{2}$, including the Harris County and nearby counties in southeastern Texas (Fig. 1).

\section{Selection of frame sites}

The main physical and mathematical properties of a reference frame are the origin, the scale, the orientation, and the change of these parameters over time. SHRF is aligned with the global reference frame (IGS08) at epoch 2012.0. The position time series of a GPS site within SHRF can be calculated by a 14-parameter Helmert transformation from its coordinates within IGS08. The position coordinates in IGS08 can be derived from Precise Point Positioning (PPP) processing.

The first step to define a regional reference frame is to select a set of reference GPS stations with good geographical distribution, long measurement histories, clean daily position time series, as well as being located on "stable" sites (e.g., Blewitt and Lavalle'e, 2002; Collilieux et al., 2007). These reference stations are often referred to "frame sites". Figure 1 shows the 10 frame sites that were selected from over 50 CORS sites in this region. Data from SG32 are archived at UNAVCO (http://facility.unavco.org/data). Data from the other 9 frame sites are archived at the NGS CORS facility (http: //geodesy.noaa.gov/CORS). The following criteria were applied to select frame stations:

1. no visible cracks in building walls and structures close to the GPS site,

2. having a data span greater than 8 years (started in 2005 or earlier),

3. no considerable subsidence observed through the visual inspection of the time series of ellipsoidal height (explained

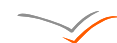

VERSITA in the last paragraph of the section "Realization of IGS08 Coordinates"),

4. having less than $0.1 \mathrm{~mm} /$ year "standard error" in calculated geocentric XYZ velocities within IGS08. The "standard error $(\sigma)^{\prime \prime}$ means there is a $95 \%$ probability that the true value of the velocity $(v)$ occurs between $v-\sigma$ and $v+\sigma$ (see Table 1).

5. having less than 4 data-discontinuities and the maximum time span between two discontinuities is less than 5 months,

6. no velocity discontinuities.

These frame sites are selected to have a well distributed reference network to minimize "network effect". The three deeply-mounted GPS antennas (ADKS, NETP, and LKHU) collocated with extensometers in the center of Houston could be regarded as stable sites (Wang and Soler, 2013). However, they are very close to each other $(<40 \mathrm{~km})$ compared to site-to-site distance among other frame sites (Fig. 1). Uneven distribution of frame sites would lead to biases in frame transformations (e.g., Collilieux et al., 2011). LKHU achieved in general lower scatters in its position time series than the other two sites. Accordingly, only LKHU was selected as a frame site in this study.

\section{Realization of IGS08 coordinates}

The PPP with single receiver phase ambiguity (SRPA) resolution employed by the GIPSY/OASIS software package (V6.1.2) was used in data processing for this study. PPP is a typical absolute positioning method using un-differenced dual-frequency pseudo-range and carrier-phase observations along with precise satellite orbit and clock information to determine the position of a stand-alone GPS station (e.g., Blewitt, 1989; Zumberge et al., 1997; Kouba and Springer, 2001; Ray et al., 2004; Kouba, 2005). The single receiver phase ambiguity method uses the wide lane and phase bias estimates obtained from a global network of ground GPS stations to perform ambiguity-resolved PPP resolution. The theoretical foundation of PPP and SRPA are documented in Zumberge et al. (1997) and Bertiger et al. (2010). Current GIPSY/OASIS users can produce an ambiguity-resolved point-positioning solution for a single receiver. The ambiguity method has significantly improved the accuracy of conventional PPP resolution, particularly in the EW component (e.g., Bertiger et al. 2010, Wang 2013a). Final satellite orbits and clocks provided by the International GNSS (Global Navigation Satellite System) Service (IGS) (Dow et al., 2009) and wide lane and phase bias estimates provided by the Jet Propulsion Laboratory (JPL) (Bertiger et al., 2010) were used in PPP processing. The major parameters estimated and key models applied in the static positioning include the VMF1 troposphere mapping model (Boehm et al., 2006), second order ionospheric delay (Kedar et al., 2003), ocean tidal loading model FES2004 (Lyard et al. 2006) calculated 
through the free online service operated by Onsala Space Observatory, Sweden (http://holt.oso.chalmers.se/loading), tropospheric gradients (Bar-Sever et al., 1998), zenith troposphere delay as a random walk with variance of $5.0 \times 10^{-8} \mathrm{~m} / \mathrm{sqrt}(\mathrm{h})$, gradient troposphere wet delay as a random walk with variance of $5.0 \times 10^{-9} \mathrm{~m} / \mathrm{sqrt}(\mathrm{h})$, receiver clock as white noise with updates every measurement epoch, and minimum elevation cutoff of 7 degrees.

The PPP-SRPA processing initially provides geocentric Cartesian coordinates $(X, Y, Z)$ within IGS08 since the IGS final fiducial orbit frame referred to IGS08 is used in GIPSY/OASIS processing. The three-dimensional Cartesian $X, Y$, and $Z$ coordinates can be converted to geodetic coordinates (latitude, longitude, and ellipsoidal height) within the same reference frame. The GPS ellipsoidal height is the height of the point relative to the reference ellipsoid surface. Orthometric height, which is referenced to a specific geoid, is often used to study vertical positions and displacements. However, the changes of ellipsoidal height and orthometric height are almost identical at a horizontally stable site during the same time span (e.g., Wang and Soler, 2012, Wang 2013b). Therefore, the ellipsoidal height time series referred to IGS08 can be directly used to interpret vertical ground deformation (subsidence or uplift). The word "vertical" always denotes a measurement along the normal direction to the reference ellipsoid throughout this article. Our previous study has indicated that subsidence rate as low as 5 $\mathrm{mm}$ per year can be identified from as short as three-year PPP daily solutions within IGS08 (Wang and Soler, 2013).

\section{Helmert transformation}

In surveying and geodesy, Helmert transformation is often used to transforms a set of points from one reference frame into another. The transformation of GPS coordinate time series from one reference frame to another could be performed with a daily 7-parameter Helmert transformation or a14-parameter similarity transformation. The 14-parameter approach is implemented in this study, which includes 3 translations, 3 rotations, 1 scale, and their rates. The coordinates of a station within SHRF can be approximated by the following equations (e.g., Snay 1999):

$$
\begin{aligned}
X(t)_{S H R F}= & T_{X}(t)+[1+s(t)] \cdot X(t)_{I G S 08}+R_{Z}(t) \cdot Y(t)_{I G S 08} \\
& -R_{Y}(t) \cdot Z(t)_{I G S 08}
\end{aligned}
$$

$$
\begin{aligned}
Y(t)_{S H R F}= & T_{Y}(t)-R_{Z}(t) \cdot X(t)_{I G S 08}+[1+s(t)] \cdot Y(t)_{I G S 08} \\
& +R_{X}(t) \cdot Z(t)_{I G S 08}
\end{aligned}
$$

$$
\begin{aligned}
Z(t)_{S H R F}= & T_{Z}(t)+R_{Y}(t) \cdot X(t)_{I G S 08}-R_{X}(t) \cdot Y(t)_{I G S 08} \\
& +[1+s(t)] \cdot Z(t)_{I G S 08}
\end{aligned}
$$

Here, $T_{X}(t), T_{Y}(t)$, and $T_{Z}(t)$ are translations along $X-, Y$-, and $Z$ axis; $R_{X}(t), R_{Y}(t)$, and $R_{Z}(t)$ are counterclockwise rotations about these three axes; $s(t)$ is a differential scale factor between IGS08 and SHRF. Continuous GPS observations have enabled us to directly calculate these 7-Helmert-parameters day by day using daily coordinates of reference stations in the two frames. However, calculating daily 7-Helmert transformation parameters is too complex for most end users, because users have to include a large number of reference stations in their PPP processing, though they may only need positions at one site. In practice, each of these 7 quantities can be regarded as a function of time. Previous studies (e.g., Snay, 2003; Soler and Snay, 2004; Pearson and Snay, 2013) have indicated that the time series of these 7 parameters can be modeled with a linear regression model and calculated by the following equations:

$$
\begin{aligned}
& T_{X}(t)=T_{X}\left(t_{0}\right)+T_{X}^{\prime} \cdot\left(t-t_{0}\right) \\
& T_{Y}(t)=T_{Y}\left(t_{0}\right)+T_{Y}^{\prime} \cdot\left(t-t_{0}\right) \\
& T_{Z}(t)=T_{Z}\left(t_{0}\right)+T_{Z}^{\prime} \cdot\left(t-t_{0}\right) \\
& R_{X}(t)=R_{X}\left(t_{0}\right)+R_{X}^{\prime} \cdot\left(t-t_{0}\right) \\
& R_{Y}(t)=R_{Y}\left(t_{0}\right)+R_{Y}^{\prime} \cdot\left(t-t_{0}\right) \\
& R_{Z}(t)=R_{Z}\left(t_{0}\right)+R_{Z}^{\prime} \cdot\left(t-t_{0}\right) \\
& s(t)=s\left(t_{0}\right)+s^{\prime} \cdot\left(t-t_{0}\right)
\end{aligned}
$$

Here, $t_{0}$ denotes a specific epoch (e.g., 2012.0). $T_{X}\left(t_{0}\right), T_{Y}\left(t_{0}\right)$, $T_{Z}\left(t_{0}\right), R_{X}\left(t_{0}\right), R_{Y}\left(t_{0}\right), R_{Z}\left(t_{0}\right)$, and $s\left(t_{0}\right)$ are the 7 Helmertparameters at epoch $t_{0}$, which are all constants. $T_{X}^{\prime}, T_{Y}^{\prime}, T_{Z}^{\prime}, R_{X}^{\prime}$, $R_{Y}^{\prime}, R_{Z}^{\prime}$, and $s^{\prime}$ are the first-time derivatives (rates) of these 7 parameters, which are also assumed to be constants. The units of these parameters are meters for translational components $\left(T_{X}(t)\right.$, $\left.T_{Y}(t), T_{Z}(t)\right)$, radians for three rotational components $\left(R_{X}(t)\right.$, $\left.R_{Y}(t), R_{Z}(t)\right)$, meter/year for the rate of translational movements $\left(T_{X}^{\prime}, T_{Y}^{\prime}, T_{Z}^{\prime}\right)$, and radian/year for rotational components $\left(R_{X}^{\prime}, R_{Y}^{\prime}\right.$, $\left.R_{Z}^{\prime}\right) \cdot s(t)$ is a unitless scale factor. The unit of $s^{\prime}$ is $1 /$ year. The equations given above serve to transform IGS08 positional coordinates to SHRF positional coordinates in this study.

\section{Calculating 14 transformation parameters}

Helmert transformation parameters can be calculated using a set of individual identical points with known coordinates in reference systems before and after the transformation. Since a total of seven parameters have to be determined, at least two points and one coordinate from a third point must be known. Thus, a system of linear equations with seven equations and seven unknowns can be solved. While the method is mathematically rigorous, it is almost impossible to get satisfied parameters with only three common points, as these points may contain observational errors. In practice, additional points are often used to obtain higher accuracy of these parameters with the least squares iteration routine.

Figure 2 illustrates the time series of the $X, Y$, and $Z$ coordinates for the 10 frame sites within the Earth-Centered Earth-Fixed (ECEF)

\section{VERSITA}


Cartesian coordinate system referred to IGS08. Several of these frame stations were subjected to instant position changes due to equipment changes or other unidentified causes. These instant coordinate changes were manually corrected by adjusting antenna heights in the PPP processing. Certain outliers had been removed by employing a two-criterion outlier removing approach developed from Firuzabadi and King (2011) and Wang (2011). Removed outliers account for approximately $7 \%$ of the total samples on average. After removing outliers, a linear regression model using the least square method was applied to fit the "cleaned" coordinate time series and calculate the velocity of each component $(X, Y, Z)$. Two of these 10 frame stations (LKHU, PATT) began operating prior to the year 2000. LKHU started to collect data since March 1993. PATT began collecting data in May 1997 and was discontinued in October 2009. PATT was also used as a frame site by the Stable North America Reference Frame (SNARF) (e.g., Herring, 2006; Blewitt, 2008). We found that the daily position time series before the year 2000 contains frequent gaps and greater noise than data after 2000. In order to achieve the best linear modeling for the position coordinate time series ( $\mathrm{X}, \mathrm{Y}, \mathrm{Z})$, this study used data collected after epoch 2000.0 in calculating the velocities.

Table 1 lists averaged XYZ coordinates of these 10 frame sites at epoch 2012.0 and the velocities along $X, Y$, and $Z$ axes within IGS08. The standard deviations of these 10 velocities are less than $1 \mathrm{~mm}$ per year. The XYZ coordinates listed in Table 1 are calculated with the following equation:

$$
\bar{X}(2012)=\sum_{i=1}^{n}(X(i)+(2012.0-t(i)) \times V) / n
$$

Here $X(i)$ represents coordinate time series of one component in IGS08; $t(i)$ represents epochs; $n$ is the number of total samples, and $V$ is the velocity. Since the two frames are aligned at epoch 2012.0, $\bar{X}(2012)$ can be regarded as the coordinates in both frames at epoch 2012.0:

$$
\begin{aligned}
& X_{\text {IGS08 }}(2012)=\bar{X}(2012), \\
& X_{\text {SHRF }}(2012)=\bar{X}(2012) .
\end{aligned}
$$

The coordinates of these common sites in both IGS08 and SHRF can be modeled with a linear regression. The velocities in SHRF can be regarded as zeros since SHRF is defined as a strictly stable frame. For example, the coordinates at epoch 2000.0 can be calculated through the following equations:

$$
\begin{gathered}
X_{I G S 08}(2000)=X_{I G S 08}(2012)+(2000.0-2012.0) \times V, \\
X_{\text {SHRF }}(2000)=X_{\text {SHRF }}(2012) .
\end{gathered}
$$

The coordinates of these 10 common points within both IGS08 and SHRF are available now, so the 7 parameters for Helmert transformation at epochs 2012.0 and 2000.0 can be calculated. The results are listed in Table 2. The rates of these Helmert parameters $\left(T_{X}^{\prime}\right.$, $T_{Y}^{\prime}, T_{Z}^{\prime}, R_{X}^{\prime}, R_{Y}^{\prime}, R_{Z}^{\prime}$, and $\left.s^{\prime}\right)$ can be obtained by a simple differential method. For example:

$$
\begin{gathered}
T_{X}^{\prime}=\left(T_{X}(2012)-T_{X}(2000)\right) / 12.0 \\
R_{X}^{\prime}=\left(R_{X}(2012)-R_{X}(2000)\right) / 12.0 \\
s^{\prime}=(s(2012)-s(2000)) / 12.0 .
\end{gathered}
$$

Table 2 lists these 14 parameters for the Helmert transformation from IGS08 to SHRF at three epochs (2000.0, 2005.0, and 2012.0). The quality of the computed 7-parameters is assessed by the RootMean-Square (RMS) of the residuals between the fit coordinates and the original coordinates of these 10 frame sites. The RMS results were $5.6 \mathrm{~mm}$ for the spatial transformation at epoch 2000.0, $3.3 \mathrm{~mm}$ for the transformation at epoch 2005.0, and zero for the transformation at epoch 2012.0 since the two frames are aligned at this epoch.

\section{Examples of position time series and velocity vectors in SHRF}

Figure 3 illustrates position time series of two frame sites LKHU and PATT in the three reference frames: IGS08, NAD83, and SHRF. The three components represent three geodetic directions: north to south (NS), east to west (EW), and up to down (UD). The horizontal velocities in IGS08 are $2 \mathrm{~mm} /$ year along NS direction and $12 \mathrm{~mm} /$ year along EW direction. The velocities in NAD83 are much smaller, $0.5 \mathrm{~mm} /$ year in NS direction and $1.5 \mathrm{~mm} /$ year in EW direction. The velocities of all three components in SHRF are less than $0.5 \mathrm{~mm} /$ year, which can be regarded as zero. The zero velocities in SHRF indicate that both sites were stable over the past 20 years (1993-2012) for LKHU and 13 years (1997-2009) for PATT. The position time series of other 8 frame sites in SHRF also indicate the stableness of these frame sites (Fig. 4). Figure 3 also indicates that the vertical coordinates in IGS08 and SHRF are almost identical, but are slightly different from those in NAD83. The NAD83 coordinates plotted in Fig. 3 are obtained by a 14-parameter Helmert transformation from IGS08 coordinates derived from the PPP-SRPA solutions. These transformation parameters were provided by Pearson and Snay (2013), and are listed in Table 2 of this article. Table 3 lists the differences of geocentric XYZ coordinates (IGS08, epoch 2005.0) for these 10 frame sites calculated by this study and those published by NGS. The average differences of absolute coordinates are less than $1 \mathrm{~cm}$, which indicates that the IGS08 realizations of this study agree well with the official NGS IGS08 realizations. Accordingly, the NAD83 coordinates calculated by this study would be approximately identical to the official NAD83(2011) coordinates. Table 4 lists the root-mean-square (RMS) of the displacement time series for these 10 frame sites and one stable site (TXLI) in SHRF. RMS is often used to assess the precision of GPS measurements. It 
Table 1. Earth-Centered Earth-Fixed Coordinates (XYZ, IGS08, Epoch: 2012.0) and Velocities of 10 Frame Stations Derived from GIPSY PPP Solutions.

\begin{tabular}{|c|c|c|c|c|c|c|c|c|c|c|c|c|}
\hline \multirow[b]{2}{*}{ Station } & \multicolumn{6}{|c|}{ GIPSY PPP Solutions ( IGS08, Epoch: 2012.0) } & \multicolumn{3}{|c|}{ Velocity (mm/year) } & \multicolumn{3}{|c|}{$\begin{array}{l}\text { Standard Error of } \\
\text { Velocity*** (mm/year) }\end{array}$} \\
\hline & $X^{*}(m)$ & $Y^{*}(m)$ & $Z^{*}(m)$ & RMS-X (cm) & RMS-Y (cm) & RMS-Z (cm) & $V_{x}$ & $Y_{Y}$ & $V_{Z}$ & $\sigma_{V x}$ & $\sigma_{V y}$ & $\sigma_{V z}$ \\
\hline LKHU & -496256.6263 & -5510740.0104 & 3162058.0637 & 0.406 & 0.734 & 0.416 & -10.87 & 2.15 & -1.78 & 0.01 & 0.02 & 0.01 \\
\hline $\mathrm{OAKH}$ & -254149.9736 & -5476621.1339 & 3248354.1530 & 0.237 & 0.636 & 0.366 & -11.98 & 0.11 & -1.18 & 0.02 & 0.05 & 0.03 \\
\hline LESV & -311569.5672 & -5455013.0168 & 3279462.2460 & 0.219 & 0.607 & 0.317 & -12.43 & 0.43 & -1.37 & 0.01 & 0.04 & 0.02 \\
\hline TXLF & -448433.2905 & -5433128.5026 & 3299736.5824 & 0.242 & 0.63 & 0.358 & -12.50 & -0.65 & -1.24 & 0.02 & 0.05 & 0.03 \\
\hline PATT & -540765.6288 & -5400118.7023 & 3339605.9367 & 0.231 & 0.816 & 0.496 & -12.75 & -0.03 & -2.16 & 0.01 & 0.04 & 0.02 \\
\hline TXWA & -673235.3424 & -5396982.7643 & 3320684.4630 & 0.187 & 0.53 & 0.332 & -12.35 & 0.79 & -2.83 & 0.02 & 0.04 & 0.03 \\
\hline TXTA & -712254.2419 & -5450502.8781 & 3224462.5538 & 0.215 & 0.54 & 0.341 & -11.99 & 1.22 & -2.57 & 0.02 & 0.04 & 0.03 \\
\hline TXBS & -700767.6184 & -5477467.3016 & 3181271.6933 & 0.225 & 0.532 & 0.321 & -11.28 & 1.07 & -2.61 & 0.02 & 0.04 & 0.02 \\
\hline TXVA & -672698.4299 & -5551082.0617 & 3057891.8268 & 0.21 & 0.554 & 0.316 & -11.16 & 2.02 & -3.13 & 0.02 & 0.05 & 0.03 \\
\hline SG32 & -608559.2306 & -5460824.1440 & 3228077.5876 & 0.232 & 0.494 & 0.327 & -11.76 & 0.98 & -2.86 & 0.01 & 0.03 & 0.02 \\
\hline Average & & & & 0.24 & 0.61 & 0.36 & -11.91 & 0.81 & -2.17 & 0.02 & 0.04 & 0.02 \\
\hline Stand D & eviation & & & 0.06 & 0.10 & 0.06 & 0.63 & 0.88 & 0.73 & 0.01 & 0.01 & 0.01 \\
\hline
\end{tabular}

* $X, Y, Z$ are average coordinates calculated through the equation

$\bar{X}(2012)=\sum_{i=1}^{n}\left(X(i)+(2012.0-t(i)) \times V_{X}\right) / n$

**: The "standard error $(\sigma)$ " means there is a $95 \%$ probability that the true value of the velocity $(v)$ occurs between $v-\sigma$ and $v+\sigma$.

Table 2. Parameters for 14-Parameter Similarity Transformations from IGS08 to SHRF.

\begin{tabular}{cccccc}
\hline Parameter & Unit & \multicolumn{3}{c}{ IGS08 to SHRF } & IGS08 to NAD83(2011)* \\
\hline \hline & & t0 02000.0 & t0 $=2005.0$ & t0 $=2012.0$ & t0 $=1997.0$ \\
$T_{X}\left(t_{0}\right)$ & $\mathrm{cm}$ & 12.87003 & 7.50752 & 0.00000 & 99.34300 \\
$T_{Y}\left(t_{0}\right)$ & $\mathrm{cm}$ & 12.70517 & 7.41135 & 0.00000 & -190.33100 \\
$T_{Z}\left(t_{0}\right)$ & $\mathrm{cm}$ & 42.54889 & 24.82019 & 0.00000 & -52.65500 \\
$R_{X}\left(t_{0}\right) * *$ & mas**** & -13.88693 & -8.10071 & 0.00000 & 25.91467 \\
$R_{Y}\left(t_{0}\right)$ & mas & 11.26615 & 6.57192 & 0.00000 & 9.42645 \\
$R_{Z}\left(t_{0}\right)$ & mas & 3.98693 & 2.32571 & 0.00000 & 11.59935 \\
$s\left(t_{0}\right)$ & ppb**** & -16.46596 & -9.60514 & 0.00000 & 1.71504 \\
$\mathrm{RMS}-\mathrm{Fit}$ & mm & 5.64982 & 3.29570 & 0.00000 & \\
$T_{X}^{\prime}$ & $\mathrm{cm} /$ year & -1.07250 & -1.07250 & -1.07250 & 0.07900 \\
$T_{Y}^{\prime}$ & $\mathrm{cm} /$ year & -1.05876 & -1.05876 & -1.05876 & -0.06000 \\
$T_{Z}^{\prime}$ & $\mathrm{cm} /$ year & -3.54574 & -3.54574 & -3.54574 & -0.13400 \\
$R_{X}^{\prime}$ & mas/year & 1.15720 & 1.15720 & 1.15720 & 0.06667 \\
$R_{Y}^{\prime}$ & mas/year & -0.93885 & -0.93885 & -0.93885 & -0.75744 \\
$R_{Z}^{\prime}$ & mas/year & -0.33224 & -0.33224 & -0.33224 & -0.05133 \\
$s^{\prime}$ & ppb/year & 1.37220 & 1.37220 & 1.37220 & -0.10201 \\
\hline
\end{tabular}

"Source: Pearson and Snay (2013), Table 7

*** Counterclockwise rotations of axes are positive.

****mas=milliarc second. Radians to mas coefficient: 206264806.24709636; mas

to radians coefficient: 4.848137E-09.

*****: $\mathrm{ppb}=$ parts per billion 


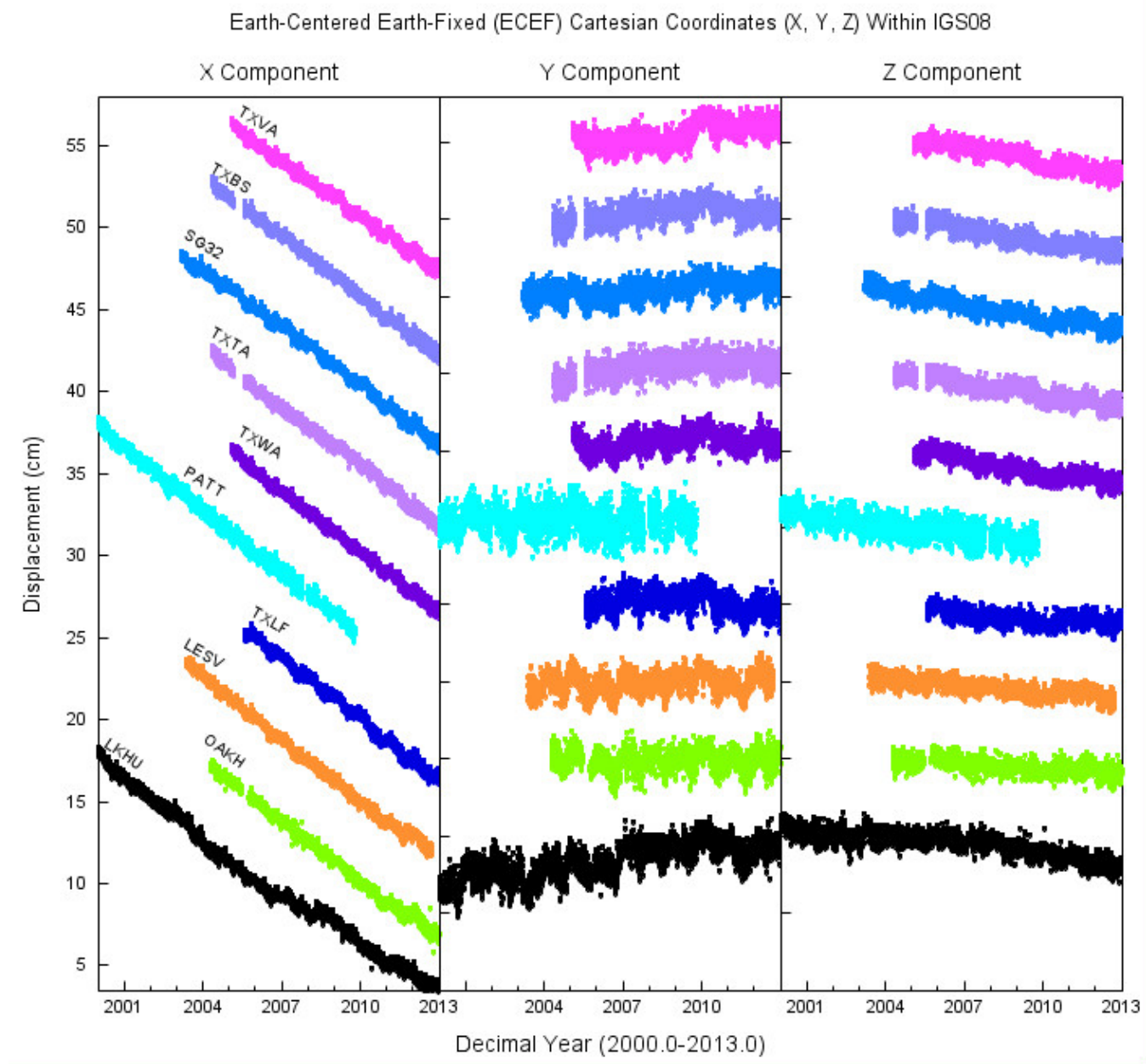

Figure 2. Positional coordinate time series (X, Y, Z) of 10 frame sites within IGS08.

Table 3. Comparisons of the IGS08 realizations (epoch 2005.0) between this study and NGS for these 10 frame sites in the geocentric coordinate system (X, Y, Z) and the geodetic coordinate system (NS, EW, UD).

\begin{tabular}{lcccccc}
\hline \multicolumn{7}{c}{ Diff.= PPP_Solution - NGS_Solution } \\
\hline Station & $\Delta \mathrm{X}(\mathrm{cm})$ & $\Delta \mathrm{Y}(\mathrm{cm})$ & $\Delta \mathrm{Z}(\mathrm{cm})$ & $\Delta \mathrm{NS}(\mathrm{cm})$ & $\Delta \mathrm{EW}(\mathrm{cm})$ & $\Delta U \mathrm{U}(\mathrm{cm})$ \\
\hline \hline LKHU & -0.12 & -0.54 & -0.28 & -0.52 & -0.10 & 0.34 \\
OAKH & 0.22 & 0.03 & -0.08 & -0.05 & 0.22 & -0.07 \\
LESV & -0.02 & -0.58 & 0.17 & -0.15 & -0.03 & 0.58 \\
TXLF & -0.30 & -0.81 & 0.51 & 0.01 & -0.33 & 0.97 \\
PATT & -0.05 & -0.11 & 0.08 & 0.01 & -0.06 & 0.14 \\
TXWA & -0.30 & -0.29 & 0.38 & 0.15 & -0.34 & 0.48 \\
TXTA & 0.31 & -2.37 & 0.28 & -0.94 & 0.27 & 2.13 \\
TXBS & -0.74 & -1.71 & 0.55 & -0.42 & -0.80 & 1.82 \\
TXVA & -0.38 & 0.82 & -0.63 & -0.17 & -0.33 & -0.99
\end{tabular}

SG32 SG32 is not a NGS CORS. NGS does not provide IGS08 coordinates.

\begin{tabular}{lllllll} 
RMS & 0.34 & 1.08 & 0.38 & 0.39 & 0.35 & 1.08 \\
\hline
\end{tabular}


Position time series at LKHU and PATT referred to IGS08, NAD83, and SHRF
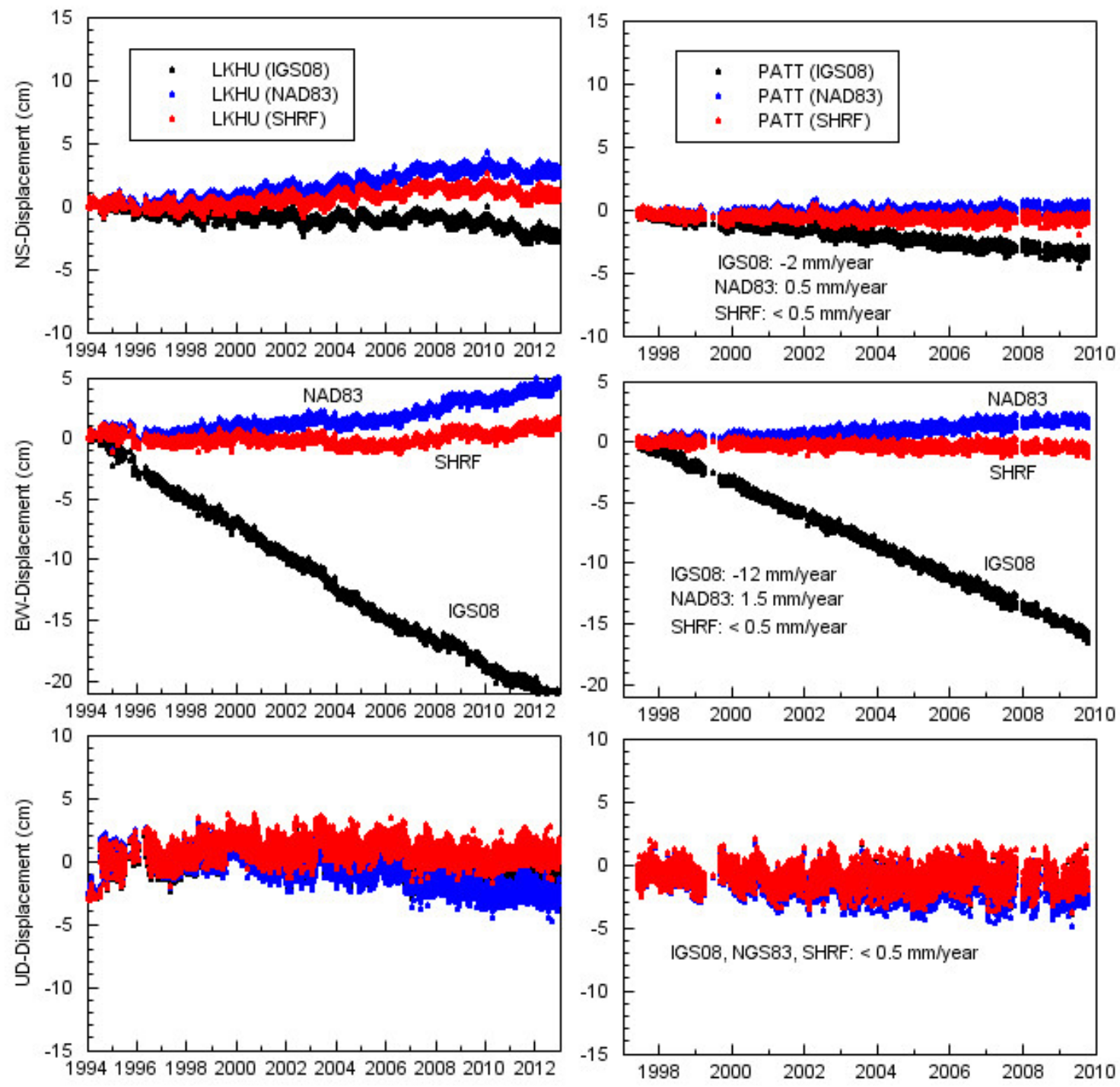

Figure 3. Comparisons of displacement time series at two frame sites (LKHU: 1994-2012; PATT: 1997-2010) referred to three reference frames: IGS08 (global, black), NAD83 (regional, blue), and SHRF (local, red).

is also called repeatability of GPS measurements. However, when contrasted with a known true position or displacement it is termed "RMS accuracy" or simply "accuracy" in geodetic literature. The average RMS accuracy of these 11 stable stations (10 frame sites plus TXLI) within SHRF is about $2.5 \mathrm{~mm}$ in the horizontal directions and $6.8 \mathrm{~mm}$ in the vertical direction. Bertiger et al. (2010) reported that PPP-SRPA solutions in IGS08 achieve accuracy of $2.1 \mathrm{~mm}$ in the NS direction, $1.9 \mathrm{~mm}$ in the EW direction, and $6.0 \mathrm{~mm}$ in the vertical direction. The number of samples used in the study of Bertiger et al. (2010) is much larger than that used in this study.
Larger sample sizes generally lead to increased accuracy in statistical studies. The consistency of accuracy of PPP-SRPA solutions in SHRF and IGS08 indicates that the frame transformation employed in this study does not affect the accuracy of original PPP-SRPA solutions.

Figure 5 shows horizontal and vertical velocity vectors of 22 CORS stations ( $>3$ years) and two PAM stations (PA01 and PA07) in the greater Houston area referred to NAD83 and SHRF. The velocities are the average velocities at each site within the time span from 2005 to 2012. Horizontal velocity vectors in NAD83 indicate a com- 
Position Time Series of 8 Frame Sites in SHRF (2005-2012)
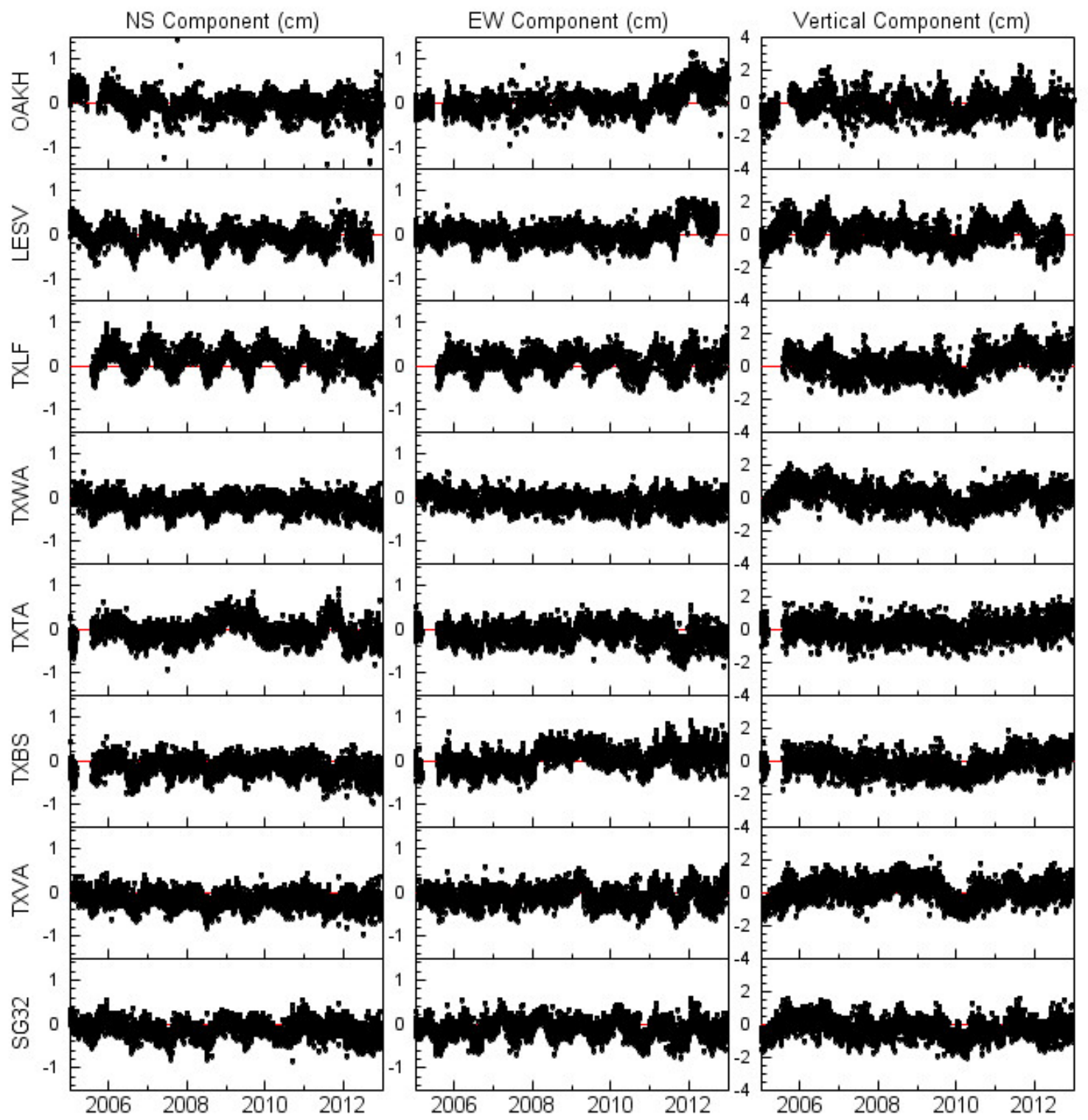

Figure 4. Position time series (NS, EW, UD) of 8 frame sites from 2005 to 2012 referred to SHRF. The position time series of other two frame sites (LKHU, PATT) are plotted in Fig. 3.

mon movement direction toward northeast, which can be easily misinterpreted as consistent local ground displacements. Using the local reference frame will avoid this kind of mistake. In fact the horizontal velocities in SHRF indicate that the horizontal ground displacements are site specific. Currently, there is not a dominant horizontal displacement direction in the studied area. Current horizontal ground deformation rates at most sites are below $3 \mathrm{~mm} /$ year (2005-2012). The vertical velocity vectors indicate that the majority of sites in the Houston area are currently experiencing subsidence

VERSITA but the rates vary by sites from below $2 \mathrm{~mm} /$ year in most places to almost $25 \mathrm{~mm} /$ year in Jersey Village. A few sites even show slight uplift, such as $\mathrm{COH} 4$ and DWI1. It seems that using NAD83 will slightly overestimate the rate of subsidence in the Houston area.

Figure 6 illustrates the three-component position time series (NS, EW, UD) referred to SHRF at three CORS sites, TXLI, TXAG and TXRO. The zero velocities ( $<0.5 \mathrm{~mm} /$ year) of all three components of TXLI indicate that this site was stable during the past 8 years (2005- 
Table 4. Geodetic coordinates (longitude, latitude, ellipsoidal height) of 11 stable sites ( 10 frame sites + TXLI) within SHRF and their RMS accuracy.

\begin{tabular}{|c|c|c|c|c|c|c|}
\hline & \multicolumn{3}{|c|}{ Geodetic Coordinates (SHRF) } & \multicolumn{3}{|c|}{ RMS Accuracy } \\
\hline & $\begin{array}{c}\text { Longitude } \\
\text { (Degree) }\end{array}$ & $\begin{array}{l}\text { Latitude } \\
\text { (Degree) }\end{array}$ & $\begin{array}{l}\text { Height } \\
\text { (m) }\end{array}$ & $\begin{array}{l}\text { NS } \\
(\mathrm{mm})\end{array}$ & $\begin{array}{l}\text { EW } \\
(\mathrm{mm})\end{array}$ & \\
\hline & & & & & 5.37 & 7.88 \\
\hline & & & & & & 6.98 \\
\hline & & & & & 2.21 & 7.08 \\
\hline TX & & & & & 2.32 & 7.01 \\
\hline & & & & & & 9.20 \\
\hline & & & & & & 6.0 \\
\hline & & & & & & 5.86 \\
\hline & & & & & & 5.87 \\
\hline TXVA & -96.9096 & 28.8349 & & 1.79 & 2.40 & 6.22 \\
\hline SG32 & -96.3589 & & & 2.09 & 2.34 & 5.69 \\
\hline & -94.7710 & 30.0559 & & & 2.04 & 6.45 \\
\hline Average & & & & 2.54 & 2.61 & 6.75 \\
\hline
\end{tabular}

* Using data after 2000.

2012). TXAG did not experience any considerable subsidence, but experienced an instant horizontal shift $(1 \mathrm{~cm})$ toward southwest in the fall of 2007. According to the field log of this site, there was no antenna change at that time. So the rapid horizontal shift in the fall of 2007 might represent real ground displacements. TXRO experienced a rapid vertical and horizontal displacement in the fall of 2009. The RMS accuracy of positions at the stable site (TXLI) is $2 \mathrm{~mm}$ in the horizontal directions and $6.5 \mathrm{~mm}$ in the vertical direction (Table 4). Figure 6 indicates that the scatters of coordinates at TXAG and TXRO (before 2009) are similar with those at TXLI, which implies that they achieved similar precision.

Figure 7 illustrates the 3-component (NS, EW, UD) displacement time series at two campaign GPS sites, PA01 and PA07, referred to SHRF. PA01 and PA07 are PAM stations operated by the HoustonGalveston Subsidence District (HGSD) for subsidence monitoring in Jersey Village. Both sites experienced significant subsidence and slight horizontal movement. The locations of these two sites are shown in Fig. 5. Jersey Village is one of the rapidly subsiding areas in Houston (e.g., Coplin and Galloway, 1999; Buckley et al., 2003; Kasmarek et al., 2009; Engelkemeir et al., 2010). PA07 experienced slightly faster subsidence than PA01. However, the overall subsidence rates at both sites have been decreasing during the past two decades. Prior to 2005, the average rate of subsidence was approximately $4.6 \mathrm{~cm} /$ year at PA01 and $5.1 \mathrm{~cm} /$ year at PA07. The current subsidence rates are approximately $1.8 \mathrm{~cm} /$ year at PA01 and $2.4 \mathrm{~cm} /$ year at PA07. Figure 7 also implies that rapid and uneven subsidence often causes considerable horizontal deformations, which would exert further damage to infrastructure and buildings on the ground.

Figure 8 illustrates the comparison of the three-component (NS,

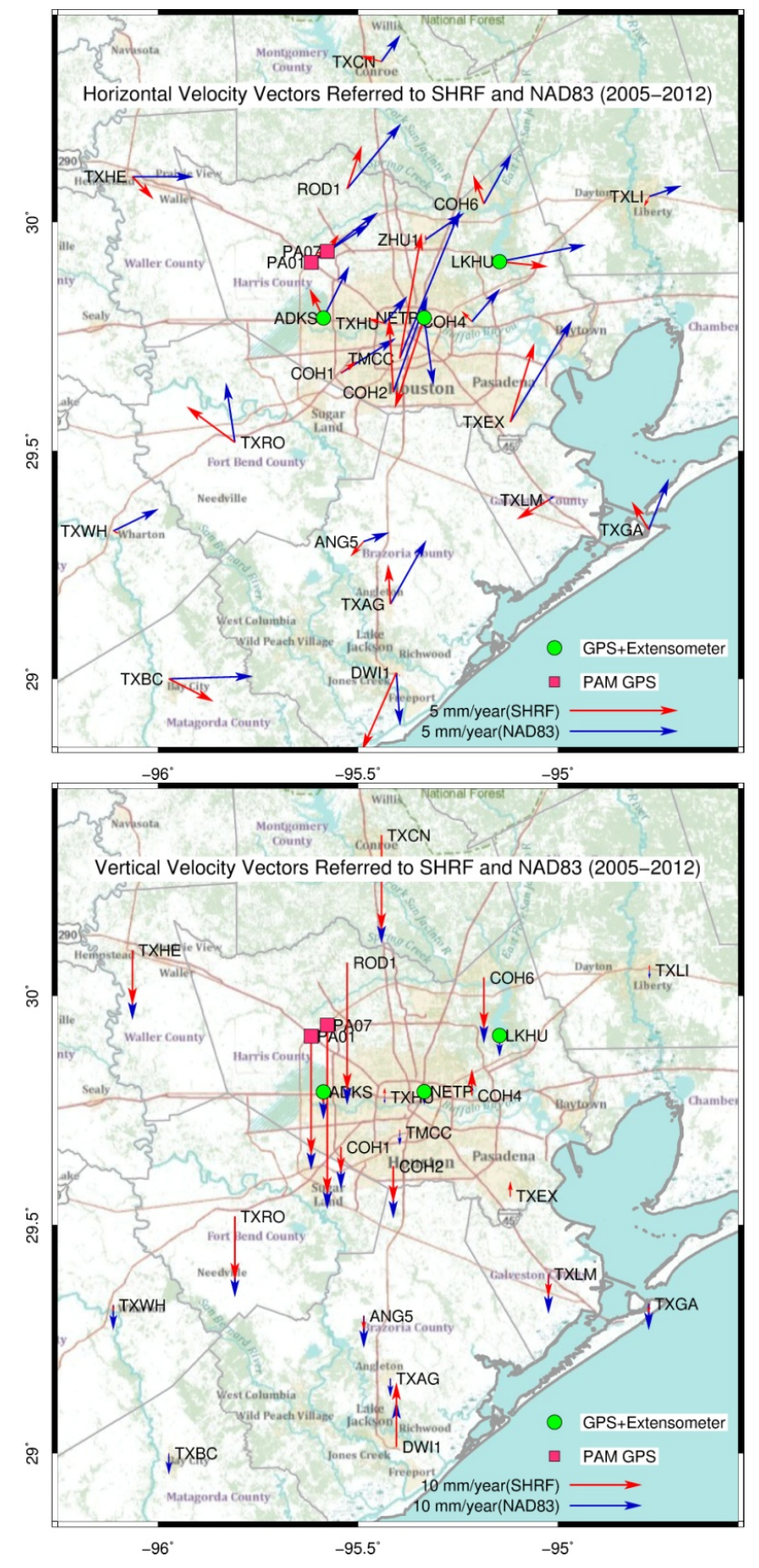

Figure 5. Horizontal and vertical velocity vectors of available continuous GPS stations in the Houston area. The vectors represent the average velocities during the past eight years (2005-2012) referred to SHRF(red) and NAD83(blue).

EW, UD) displacement time series (2000-2013) at a PAM site PA05 derived from two different posit-processing approaches: carrier phase double-difference (DD) and PPP methods. PA05 is closelyspaced with the deeply anchored CORS station ADKS at the Addicks extensometer site, which has been identified as a locally sta-

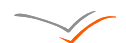

VERSITA 

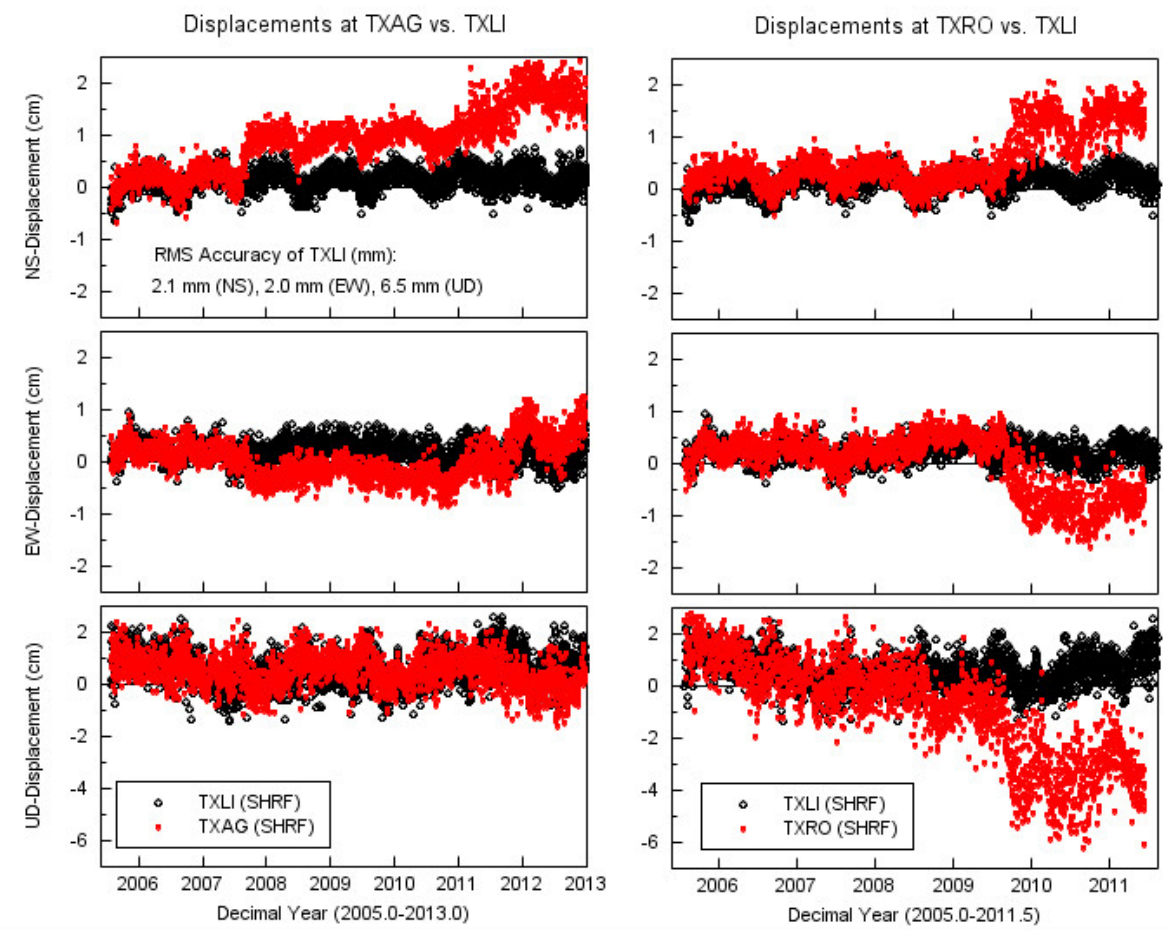

Figure 6. Displacement time series (NS, EW, UD) at three continuous GPS sites TXLI, TXAG, and TXRO referred to SHRF.
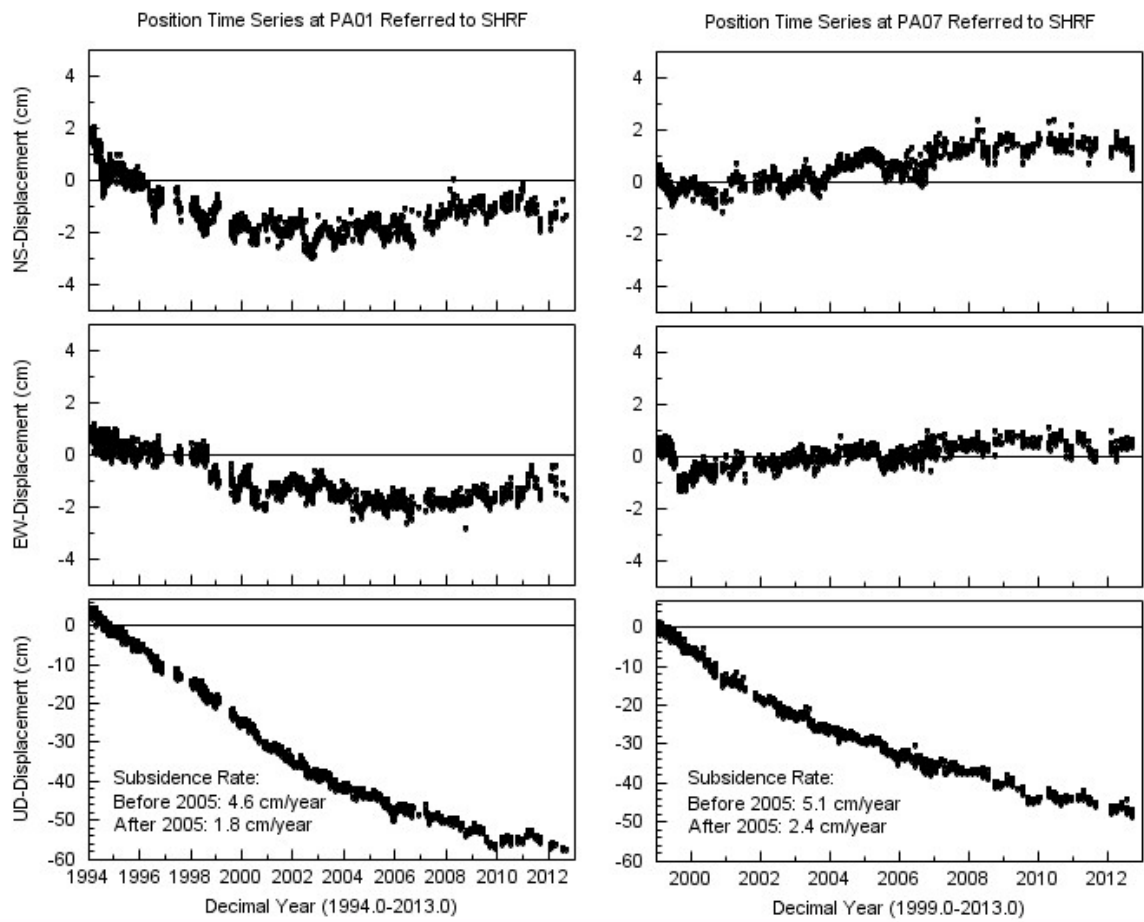

Figure 7. Displacement time series (NS, EW, and UD) referred to SHRF at two campaign GPS sites PA01 (left column) and PA07 (right column) in Jersey Village (Fig. 5). 
ble site (e.g., Zilkoski et al., 2003; Wang and Soler, 2013). The antenna pole of PA05 is anchored $6 \mathrm{~m}$ below the ground surface. The distance between PA05 and ADKS is only $50 \mathrm{~m}$. The double difference solutions are solved by fixing the position of ADKS antenna. According to our experience with the double difference post-processing method, the baseline as short as $50 \mathrm{~m}$ would lead to sub-millimeter accuracy for daily positions in all three directions (Wang, 2012). So the double difference solutions for PA05 can be regarded as "true" values to assess the frame transformation. Figure 8 indicates that the two data sets agree considerably well during the whole time span (2000-2013), which indicates that the frame transformation employed in this study is appropriate.
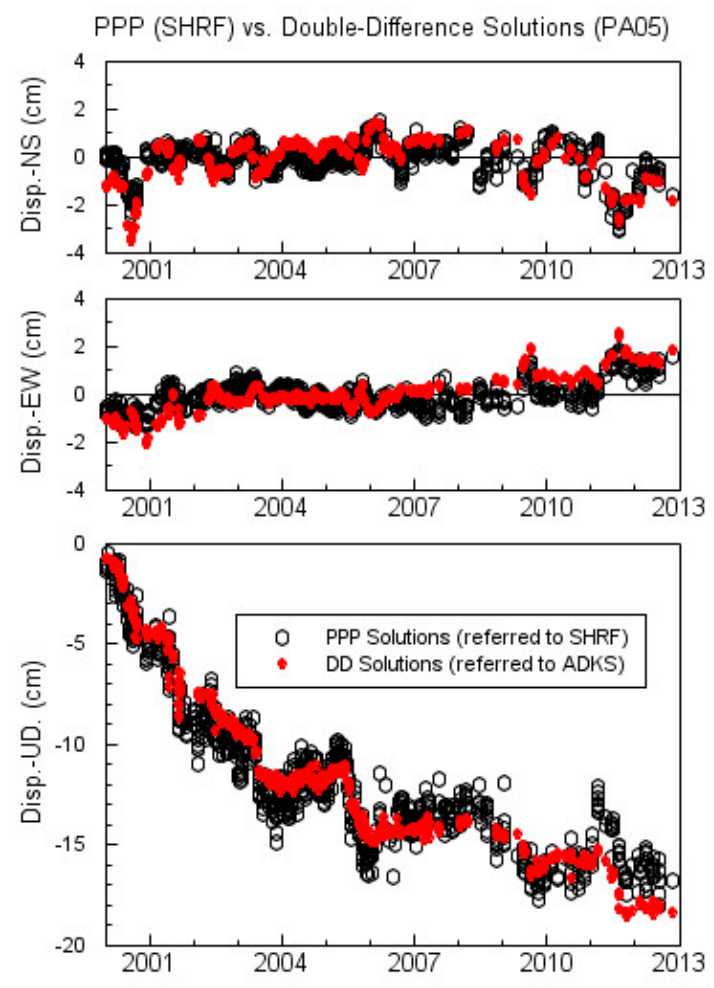

Figure 8. Three-component displacement time series (2000-2013) at PA05. Red circles represent the PPP solutions within SHRF. Dark circles represent the double-difference (DD) solutions relative to a stable GPS antenna (ADKS). The baseline is $50 \mathrm{~m}$.

\section{14-parameter vs. 12-parameter transformation}

Helmert transformation is frequently used in geodesy to produce "distortion-free" transformations from one reference frame to another. The main function of the scale factor $(s)$ is to minimize the distortion of point-to-point distance between the two reference frames. It is believed that the distortion for point-to-point distances would be minor within a small area. Thus, the scale factor could be set as zero in frame transformations from a global frame to a regional or local frame. For example, the scale factor is set as zero for the frame transformations from ITRF2000 to NAD83(PACP00) and from ITRF2000 to NAD83(MARP00) in the Horizontal Time-Dependent Positioning (HTDP) utility developed by NGS (Snay, 2003). NAD83(PACP00) is a regional reference frame for the Pacific tectonic plate. NAD83(MARP00) is a regional reference frame for the Mariana tectonic plate. SHRF covers a much smaller area compared with NAD83 reference frames. In order to check the effect of the scale factor to the frame transformation, we also performed the frame transformation from IGS08 to SHRF with 12parameters $\left(s=0 ; s^{\prime}=0\right.$ ). Figure 9 illustrates 3-component (NS, EW, UD) displacement time series (2005-2013) at two CORS stations (TXLM, TXCN) related to SHRF. The red points represent the results from a 14-parameter Helmert transformation; the dark points represent the results from a 12-parameter Helmert transformation. TXCN is located $70 \mathrm{~km}$ north of downtown Houston. TXLM is located $50 \mathrm{~km}$ south of downtown Houston and $20 \mathrm{~km}$ from the coast. The locations of these two sites are shown in Fig. 5. Figure 9 indicates that the difference of the 12-parameter and 14parameter frame transformation is almost invisible within a time span of 8 years.

\section{Discussion and conclusions}

The PPP post-processing method has attracted broad interest for static positioning because of its operational simplicity and high precision. A shortcoming of the PPP resolution is that the calculated coordinates are in a global reference frame, currently in IGS08. End users need to transform the global coordinates into local reference fames for their local applications. This study provides the detailed method needed to convert IGS08 coordinates into a local reference frame. In the first release of SHRF, the product consists of (1) accurate positions and velocities of 10 frame sites (Table 1), and (2) a 14-parameter Helmert transformation for converting coordinates from IGS08 to SHRF (Table 2).

SHRF provides a consistent and accurate reference with which scientific and geometrics results can be produced and compared in space and time. SHRF will serve the broad scientific and geometrics communities. For example, geologists and hydrologists can apply the position time series within the stable reference frame to study ground deformation due to drought, ground fluid withdrawal, aquifer deformation, seasonal hydrologic and atmospheric pressure loading, as well as fault creep and salt dome uplift; civil engineers can apply the position time series within the local reference frame to monitor the long-term stability of critical structures, such as offshore oil platforms, high-rise buildings, highway bridges, dams, and levees. SHRF will be incrementally improved and be synchronized with the update of IGS reference frame.

\section{Acknowledgments}

We thank NGS and the Harris-Galveston Subsidence District for providing GPS data to the public. We appreciates many thoughtful discussions about GPS observations in the Houston area with Mr.

\section{VERSITA}


Frame Transformation: 14 Parameters vs. 12 Parameters
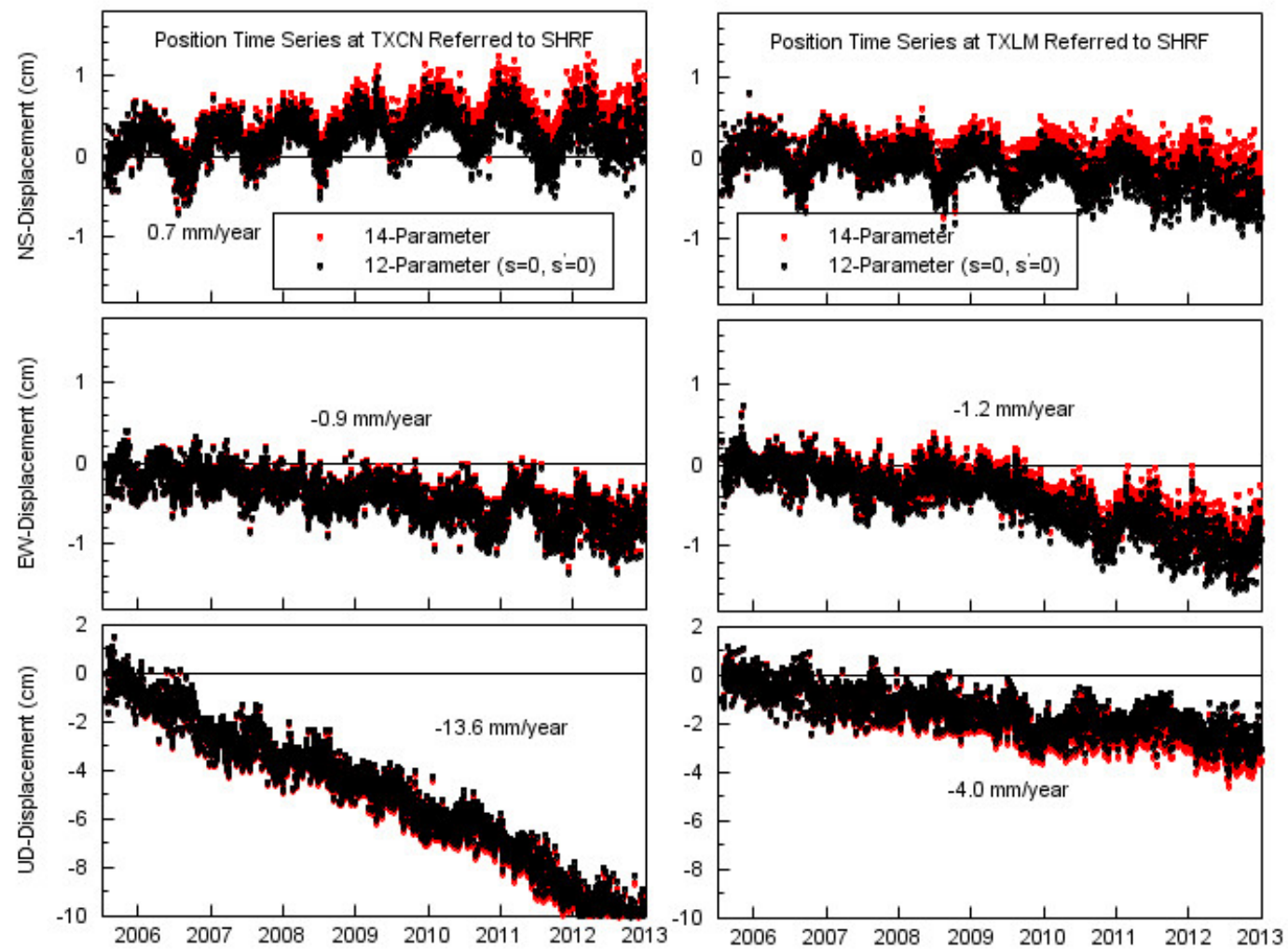

Figure 9. Displacement time series (NS, EW, UD) at two continuous GPS sites TXCN (left column) and TXLM (right column). The red and dark points represent the results from a 14-parameter and a 12-parameter Helmert transformation from IGS08 to SHRF, respectively.

Cliff Middleton, one of the NGS State Geodetic Advisors in Texas, and Mr. William M. Chrismer, GPS \& Information System Coordinator at the Harris-Galveston Subsidence District. This study was supported by a NSF CAREER award EAR-1229278 and and a NSF MRI award EAR-1242383.

\section{References}

Bar-Sever Y. E., Kroger P. M. and Borjesson J. A., 1998, Estimating horizontal gradients of tropospheric path delay with a single GPS receiver, J. Geophys. Res., 103(B3), 5019-5035.

Bertiger W., Desai S. D., Haines B., Harvey N., Moore A. W., Owen S. and Weiss J. P., 2010, Single receiver phase ambiguity resolution with GPS data, J. Geodesy, 84(5), 327-337.

Blewitt G., 1989, Carrier phase ambiguity resolution for the Global Positioning System applied to geodetic baselines up to 2000 km, J. Geopys. Res., 94(B8), 10,187-10,203.
Blewitt G., 2008, Overview of the SNARF Working Group, its activities, and accomplishments, Report of the Ninth SNARF Workshop, http://www.unavco.org/community_ science/workinggroups_projects/snarf/2008_ mar_workshop/2008_mar_workshop.html

Blewitt G., Kreemer C. W., Hammond W.H., and Goldfarb J. M., 2013, Terrestrial reference frame NA12 for crustal deformation studies in North America, J. Geodyn. (in press).

Blewitt G. and Lavalleè D., 2002, Effect of annual signals on geodetic velocity, J. Geophys. Res., 107(B7):ETG9-1-ETG911.

Boehm J., Niell A., Tregoning P. and Schuh H., 2006, Global mapping function (GMF): a new empirical mapping function based on numerical weather model data, Geopgys. Res. Lett., 33(7), 1-4.

\section{VERSITA}


Buckley S. M., Rosen P. A., Hensley S. and Tapley B. D., 2003, Land subsidence in Houston, Texas, measured by radar interferometry and constrained by extensometers, J. Geophys. Res., 108(11), 252-242.

Collilieux X., Altamimi Z., Coulot D., Ray J. and Sillard P., 2007, Comparison of very long baseline interferometry, GPS, and satellite laser ranging height residuals from ITRF2005 using spectral and correlation methods, J Geophys Res., 112(B12403), 1-18.

Collilieux X., Mètivier L., Altamimi Z., van Dam T. and Ray J., 2011, Quality assessment of GPS reprocessed terrestrial reference frame, GPS Solut. 15(3):219-231.

Coplin L. S. and Galloway D., 1999, HoustonGalveston,Texas-Managing coastal subsidence, in Galloway, D., Jones, D.R., and Ingebritsen, S.E., eds., Land subsidence in the United States. U.S. Geological Survey Circular 1182, p. 35-84.

Dow J. M., Neilan R. E. and Rizos C., 2009, The international GNSS service in a changing landscape of Global Navigation Satellite Systems, J. Geodesy, 83(3-4), 191-198.

Eckl M. C., Snay R. A., Soler T., Cline M. W. and Mader G. L., 2001, Accuracy of GPS-derived relative positions as a function of interstation distance and observing-session duration, J. Geodesy, 75(12), 633-640.

Engelkemeir R., Khan S. and Burke K., 2010, Surface deformation in Houston, Texas using GPS, Tectonophysics, 490(1-2), 47-54.

Firuzabadi D. and King R. W., 2011, GPS precision as a function of session duration and reference frame using multipoint software, GPS Solut., 16(2), 191-196.

Fort Bend Subsidence District, 2009, Fort Bend Subsidence District 2003 regulatory plan (amended 2007, 2009), Accessed February 22, 2013, at http://www .fbsubsidence.org/ assets/pdf/FBRegPlan.pdf.

Gabrysch R. K., 1984, Ground-water withdrawals and land surface subsidence in the Houston Galveston region, Texas, 1906-90, Texas Department of Water Resources, Report 287, $64 \mathrm{p}$.

Harris Galveston Subsidence District, 2010, District regulatory plan 1999 [amended 2001, 2010], Accessed February 22, 2013, at http: //www.hgsubsidence.org/assets / pdfdocuments/HGRegPlan.pdf.
Herring T. A., 2006, SNARF realization for PBO processing, presentation given at the 5th SNARF Workshop, held in Denver, CO, March 2006. Accessed February 23, 2013 at http: / /www . unavco.org/community_science/ workinggroups_projects/snarf/2006_nov_ workshop/2006_nov_workshop.html

Herring T. A., King R. W. and McCluskey S. M., 2009, Introduction to GAMIT/GLOBK, release 10.35, Mass. Instit. of Tech., Cambridge.

Kasmarek M. C., Gabrysch R. K. and Johnson M. R., 2009, Estimated Land-Surface Subsidence in Harris County, Texas, 1915-17 to 2001, U.S. Geological Survey Scientific Investigations, Map 3097, 2 sheets.

Kasmarek M. C., Johnson M. R. and Ramage J. K., 2012, Water-level altitudes 2012 and water-level changes in the Chicot, Evangeline, and Jasper aquifers and compaction 1973-2011 in the Chicot and Evangeline aquifers, Houston-Galveston region, Texas, U.S. Geological Survey Scientific Investigations, Map 3230, 18 p., 16 sheets.

Kedar S., Hajj G. A., Wilson B. D. and Heflin M. B., 2003, The effect of the second order GPS ionospheric correction on receiver positions, Geophys. Res. Lett. 30(16), 1144-1146.

Kouba J., 2005, A possible detection of the 26 December 2004 great Sumatra-Andaman Islands earthquake with solution products of the int. GNSS service, Studia Geophysica et Geodaetica, 49(4), 463-383.

Kouba J. and Springer T., 2001, New IGS station and satellite clock combination, GPS Solut. 4(4), 31-36.

Lyard F., Lefevre F., Letellier T. and Francis O., 2006, Modelling the global ocean tides: modern insights from FES2004, Ocean Dynam., 56(5-6), 394-415.

Pearson C., McCaffrey R., Elliot J. L. and Snay R., 2010, HDTP 3.0: Software for copying with the coordinate changes associated with crustal motion, J. Surv. Eng., 136(2), 80-90.

Pearson P. and Snay R., 2013, Introducing HTDP 3.1 to transform coordinates across time and spatial reference frames, GPS Solut., 17(1), 1-17.

Poland J. F., Yamamoto S. and Working Group, 1984, Field measurement of deformation, in Guidebook to studies of land subsidence due to ground-water withdrawal, edited by Poland, J. F., published by United Nations Educational 
Scientific and Cultural Organization (UNESCO), Paris, France, p. 17-35.

Ray J., Dong D. and Altamimi Z., 2004, IGS reference frames: status and future improvements, GPS Solut., 8(4), 251-266.

Rebischung P., Griffiths J., Ray J., Schmid R., Collilieux X. and Garayt B., 2012, IGS08: the IGS realization of ITRF2008, GPS Solut., 16(4), 483-494.

Shah S. D. and Lanning-Rush J., 2005, Principal faults in the Houston, Texas, Metropolitan Area, USGS, Scientific Investigations Map 2874, http://pubs.usgs.gov/sim/ $2005 / 2874$

Schwarz C. R., 1989, The North American Datum of 1983, National Geodetic Survey, Rockville, MD 20852, December 1989. http://ontario.worldlibrary.net/ Members/NOAA_Library/NADof 1983.pdf

Snay R. A., 1999, Using HTDP software to transform spatial coordinates across time and between reference frames, Surv. Land Inf. Syst., 59, 1, 15-25.

Snay R. A., 2003, Introducing Two Spatial Reference Frames for Regions of the Pacific Ocean, Survey and Land Information Science, 63, 1, 5-12.

Snay R. A. and Soler T., 2000, Modern Terrestrial Reference Systems. Part 2: The evolution of the NAD 83, Professional Surveyor, 20, 2, 16-18.

Soler T. and Snay R. A., 2004, Transforming positions and velocities between the International Terrestrial Reference Frame of 2000 and North American Datum of 1983, J. Surv. Eng., 130, 2, 49-55.

Wang G., 2011, GPS Landslide Monitoring: Single Base vs. Network Solutions, a case study based on the Puerto Rico and Virgin Islands Permanent GPS Network, J. Geod. Sci., 1, 3 , 191-203.

Wang G., 2012, Kinematics of the Cerca del Cielo, Puerto Rico landslide derived from GPS observations, Landslides, 9, 1, 117-130.

Wang G., 2013a, Millimeter-Accuracy GPS Landslide Monitoring Using Precise Point Positioning with Single Receiver Phase Ambiguity Resolution: A Case Study in Puerto Rico, J. Geod. Sci., 3, 1, 22-31.

Wang G., 2013b, Teaching High-Accuracy GPS to Undergraduates Using Online Processing Services, J. Geos. Edu. 61, 2, 202-212.

Wang G. and Soler T., 2012, OPUS for Horizontal Subcentimeter-Accuracy Landslide Monitoring: A Case Study in the Puerto Rico and Virgin Islands Region, J. Surv. Eng., 138, 3, 143-153.

Wang G. and Soler T., 2013, Using OPUS for Measuring Vertical Displacements in Houston, TX, J. Surv. Eng., 139(3), 126-134, doi: 10.1061/(ASCE)SU.1943-5428.0000103, http://dx . doi .org/10.1061/(ASCE) SU . 1943-5428.0000103

Zilkoski D. B., Hall L.W., Mitchell G. J., Kammula V., Singh A., Chrismer W. M. and Neighbors R. J., 2003, The HarrisGalveston Coastal Subsidence District/National Geodetic Survey Automated Global Positioning System Subsidence Monitoring Project, Proceedings of the U.S. Geological Survey Subsidence Interest Group Conference, OFR. 03-308, p13-28.

Zumberge J., Heflin M., Jefferson D., Watkins M. and Webb F., 1997, Precise point positioning for the efficient and robust analysis of GPS data from large networks, J. Geophys. Res., 102, B3, 5005-5017. 